\title{
Determination of Optimum Renewable Energy Sources for Public Libraries
}

\author{
B. Dursun
}

\begin{abstract}
Energy has the key role for the socio-development of a country. Today, the reaching end of the fossil fuels indicates the energy straits in the near future. From this point of view, countries could use renewable energy sources based on their potentials. Recently, particularly structures intensively use renewable energy sources. Hence, renewable energy sources are planned to be used public library buildings. Via optimum hybrid system consisting of joint wind and solar energy resources usage, energy need of Kirklareli city public library will be provided. Parameters like the optimum wind turbine, converter number solar panel and battery are to be determined by analyses.
\end{abstract}

Index Terms - Public Libraries, Renewable Energy

\section{INTRODUCTION}

$\mathrm{D}$ ECREASING dependency on fossil fuels in the world has necessitated an urgent search for renewable energy sources to meet the present days' demand. Another key reason to reduce our reliance on fossil fuels is the growing evidence of the global warming phenomena. The use of solar and wind energy has become increasingly significant, attractive and cost-effective, since the oil crises of early 1970s. However, stand-alone solar or wind energy systems can never provide a continuous energy supply due to seasonal and periodical variations. In order to cope with this difficulty, hybrid power systems which include one or more renewable energy based generating units such as solar and wind generating units are combined with battery backups to satisfy the load demand available [1-4].

Wind and solar hybrid power systems are gaining popularity for stand-alone power generation applications, due to the advances in renewable energy technologies and subsequent rise in prices of petroleum products. The economic aspects of these technologies show sufficient promise to include them in developing power generation capacity for developing countries [4].

In this study, firstly, type and combinations of the renewable energy generating systems is introduced for public libraries in detail. Then, it is intended to meet the energy demand of the Kurklareli Public Library by using hybrid solar and wind energy generating system. Wind and solar data of Kirklareli province was obtained from EIE for the years between 2010 and 2014. The energy need of Kırklareli city public library will be provided with optimum hybrid system consisting of wind and solar energy resources usage.

B. Dursun, is with the, Energy Systems Engineering Department, Kirklareli University, Kirklareli, Turkey, (e-mail: bahtiyar.dursun@klu.edu.tr).
The parameters such as the optimum wind turbine, solar panel, converter number and battery are going to be ascertained by analysis.

\section{PUBLIC LiBRARIES IN TURKEY}

Turkey's public libraries in have been administered by the Ministry of Culture and Tourism, General Directorate of Libraries and Publications since 1960. The population of Turkey is about 71 million and Turkey is divided into 7 large geographic regions with 81 provinces. The General Directorate of Libraries is the largest department within the Ministry in terms of its budget and personnel. The children's libraries operating under the MCT, are mainly established in the public libraries. Some of the children's libraries have their own building in spite of the fact that there has been a recent trend towards having children libraries within the public libraries. In addition to these there are a few municipal libraries governed and financed by the local authorities $[5,6]$.

\section{RENEWABLE POWER GENERATING SYSTEM OPTIONS IN PUBLIC LIBRARY}

\section{A. PV/diesel hybrid system}

The hybrid power system is constituted by diesel generator, PV arrays, batteries and power converters. The block diagram of $\mathrm{PV} /$ diesel hybrid power system components are given in Figure 1.

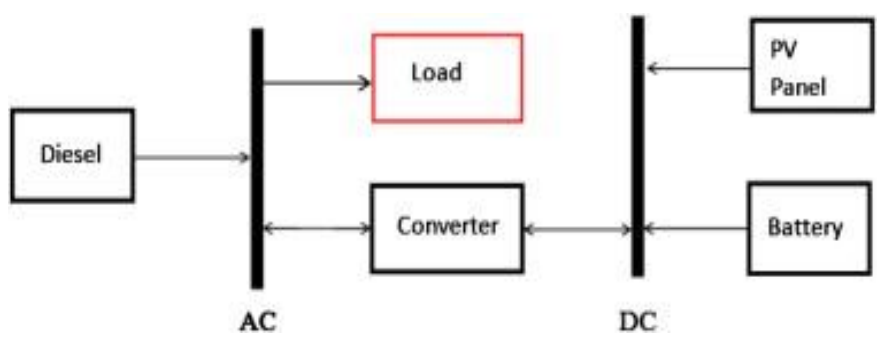

Fig.1. The block diagram of PV/diesel hybrid power system

B. The grid connected PV power system

The grid connected PV power system is powered by the grid and different from the standalone PV/diesel hybrid power system, it does not include diesel generator. All components of the hybrid power system are the same with the ones in the standalone $\mathrm{PV} /$ diesel hybrid power system mentioned in the 
previous section. All of components of the hybrid power system are shown in Figure 2.

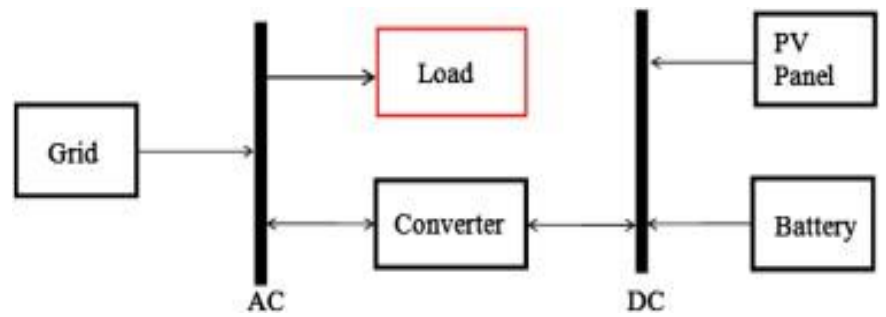

Fig.2. The block diagram of the grid connected PV power system

\section{PV/wind power generating system}

The hybrid power system is made up by wind turbine, $\mathrm{PV}$ arrays, batteries and power converters. The schematic diagram of $\mathrm{PV} /$ wind hybrid power system components are shown in Figure 3.

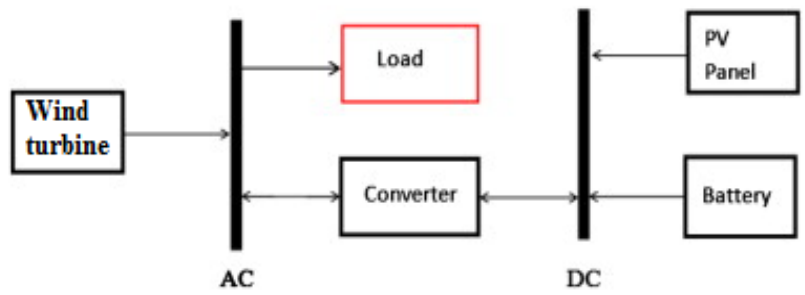

Fig.3. The block diagram of PV/wind hybrid power system

\section{Grid Connected Wind power system}

The grid connected wind power system is powered by the grid and it includes no PV arrays unlike the standalone PV/wind hybrid power system. Wind turbine, batteries and power converters form the hybrid power system. All of the components of the hybrid power system are indicated in Figure 4.

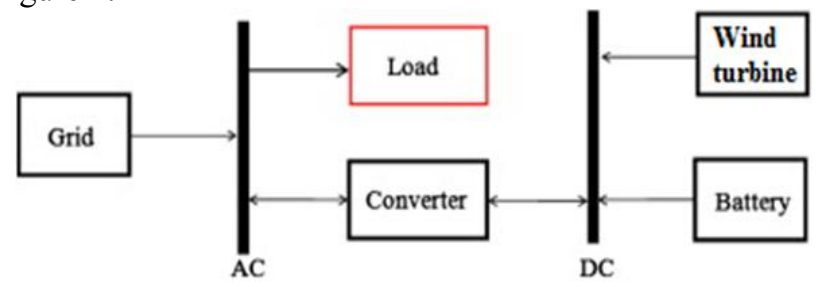

Fig.4. The grid connected wind power system

\section{HYBRID SOLAR AND WIND POWER GENERATING SYSTEM FOR KIRKLARELI PUBLIC LIBRARY}

Kirklareli public library has two conference halls, an exhibition hall, an Internet access center, reading halls for children, three purposed reading halls, and a section for collections and rare books. Monthly electricity consumption in Kurklareli public library is $900 \mathrm{~kW}-1200 \mathrm{~kW}$, depending on the time of the year, the bulk of which is consumed in Kirklareli public library by the artificial lighting system, the outdoor garden, and computers. In this case, monthly consumption falls between $30 \mathrm{~kW}$ to $40 \mathrm{~kW}$. Figure 5 gives the daily energy consumption for Kurklareli Public Library, where nighttime energy consumption is exclusively for garden lighting.

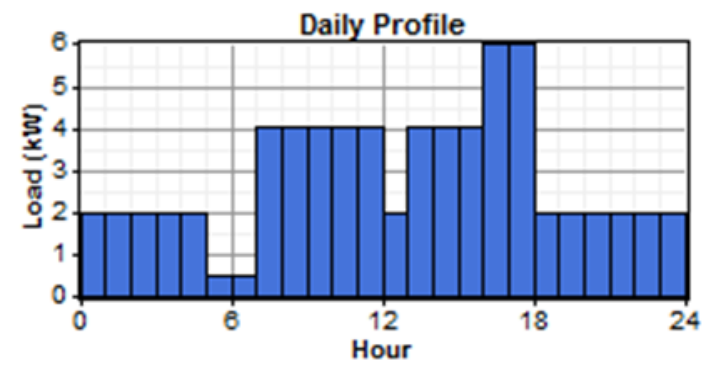

Fig.5. The energy demand of Kırklareli Public Library

The hybrid power system model proposed to meet the energy demand of Kirklareli Public Library is provided in Figure 6. The energy demand is to be supplied by the energy produced using PV and wind turbines, which generate DC electricity. The voltage thus generated is then converted into $\mathrm{AC}$ via a converter, which ultimately provides the energy required.

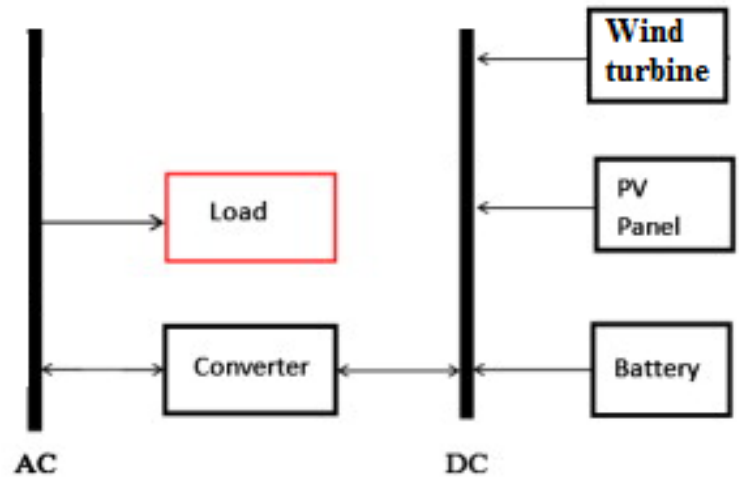

Fig.6. Proposed hybrid power system model for Kırklareli Public Library

Figure 7 gives the hourly wind speed of the campus. Clearly, the wind speed ranges from $3 \mathrm{~m} / \mathrm{s}$ to $5 \mathrm{~m} / \mathrm{s}$, with an average speed of $3.94 \mathrm{~m} / \mathrm{s}[8]$.

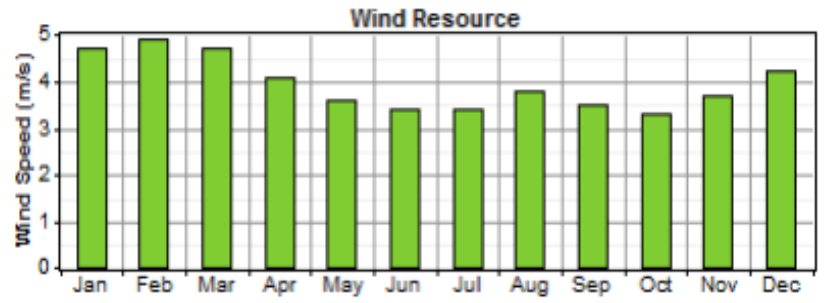

Fig.7. Annually wind speed distribution of the region

Figure 8 uses data taken from Turkish State Meteorological Service (TSMS) for the year 2010 [9], monthly to provide the average monthly solar energy density values. The annual average solar energy density, on the other hand, is calculated to be $4.98 \mathrm{kWhm}^{-2} \mathrm{~d}^{-1}$, with a scaled annual average clearness index of 0.503 [10]. 


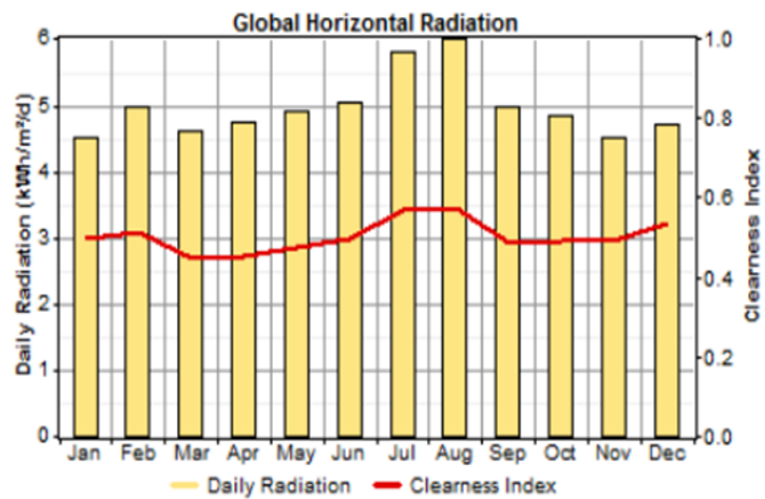

Fig.8. Daily radiation and clearness index profile of the nearest region to the Kırklareli public library

HOMER does energy balance calculations for each hour in a year to simulate the operation of a system. Since the hourly load profiles are not always available for the whole year, HOMER is used to synthesize the load profiles (at random) after entering the values for a typical day. In the study, day-today or step-to-time-step randomness is taken to be 5\% [11].

\section{COMPONENT OF THE HYBRID POWER SYSTEMS}

The PV/Wind system contains four major components: PV modules, wind turbines, batteries, and a converter. Figure 6 schematizes a typical hybrid system, which contains generators, wind turbines, photovoltaic modules, inverters, and a battery bank. For our purposes, the properties of the major components of the hybrid system need to be determined so as to supply the required user AC load efficiently.

\section{A. PV Panel}

Such a hybrid system takes solar energy, one source of renewable energy that exists in Turkey in abundance, to be one of the basic load suppliers. Each PV module is rated at $100 \mathrm{~W}$, with a nominal voltage of $12 \mathrm{~V}$. Note that this PV array can only generate power during daytime, i.e. from 6 a.m. to 6 p.m. That means that the output power of the solar energy system is $0 \mathrm{~W}$ during nighttime. To compensate for this discrepancy, the task of supplying energy will have to be taken over by either or a combination of the battery, the generators, or the wind turbines. Regarding the economy of the system, we make the following assumptions about the specifications of the PV module:[10]

- The cost of each $\mathrm{kW}$ of PV module is $\$ 7200$.

- The cost of replacement is the same as the initial cost.

- Operating and maintenance cost, being negligible, is assumed to be zero.

- To determine the most feasible configuration of the hybrid system, the number of the $1 \mathrm{~kW}$ PV module ranges from 0 to 5 .

\section{B. Wind Turbine}

Wind energy, another renewable energy source, is also abundant in Turkey, making it one of the basic load suppliers. Wind turbines are used to convert wind energy into usable forms of energy. In the case of a regional AC load demand, the DC power generated by wind turbines and the PV panels of the hybrid system would be converted into AC through inverters, which would subsequently be fed into the system to supply the AC load demand. The hybrid system uses the SW AIR X wind turbines, which have an output power capacity of $0.5 \mathrm{~kW}$ and a lifetime of 20 years [12]. Speaking for economy, the wind turbine has an initial cost of $\$ 1200$, a replacement cost of $\$ 1100$, and a yearly operating and maintenance cost of $\$ 20$. In the economy analysis of the HOMER software, the number of the wind turbine ranges from 0 to 3 determines the most feasible configuration of the hybrid system.

\section{Storage battery}

For storage, the hybrid system uses the TROJAN T-105 battery, which has a nominal capacity of 225Ah, and a nominal voltage of $6 \mathrm{~V}$. A single battery stores $1.35 \mathrm{~kW}$ of energy, with the value being calculated by multiplying voltage with current capacity. The battery bank is designed to contain a total of 6 strings, each with two batteries, ultimately yielding 12 units of battery with a bus nominal voltage of $12 \mathrm{~V}$. in the HOMER software, this number ranges from 0 to 10 with an increment of 12 batteries. Overall, the battery is predicted to have an initial cost of $\$ 1100$, a replacement cost of $\$ 100$, and an annual operating and maintenance cost of \$10 [13].

\section{Inverter}

To supply the maximum $8.49 \mathrm{~kW} / \mathrm{h}$ peak load of the library, $1 \mathrm{~kW}$ is chosen as the rated power of the inverter. This can fully supply both the PV power and the excess power of the wind turbine, which will have leftover energy after meeting the load demand. Since the inverter has an efficiency of $90 \%$, the power supplied will be below $6 \mathrm{~kW}$. The inverter has an initial cost of $\$ 200$ per $\mathrm{kW}$, which is the same as the replacement cost, and no operating and maintenance cost.

\section{RESULTS AND DISCUSSIONS}

The purpose of the optimization process is to determine the optimal value of each decision variables such as the number of wind turbines, the number of batteries, the size of AC-DC converter. In this study, in the optimization process, HOMER simulates many different system configurations, discards the infeasible ones, ranks the feasible ones according to total net present cost, and presents the feasible one with the lowest total net present cost as the optimal system configuration.

For the current conditions which are defined as average wind speed, average solar global irradiance and primary load are almost $3.57 \mathrm{~m} / \mathrm{s}, 3 \mathrm{kWh} / \mathrm{m}^{2} / \mathrm{d}$ and $0.25 \mathrm{kWh} / \mathrm{d}$ respectively, according to the simulation results. For the public library, the optimal configuration with the lowest total net present cost (NPC) contains one wind turbine, two batteries, the $1 \mathrm{~kW}$ converter. Total NPC of the optimal configuration described in the part of discussion is predicted to be $\$ 4319$ and its COE is around $4.127 \$ / \mathrm{kWh}$.

Because the sensitivity analysis is conducted by means of HOMER in this study, following situations are taken into account.

- Wind speed value is considered changing in the range of 3.5 - $5.5 \mathrm{~m} / \mathrm{s}$ (which covers wind speed values which are $30 \%$ lower and higher than the current value) because of the wind's variable and unsteady nature. In this simulation, it is also 
handled the effect of the varying wind speed values on the cost of the energy generated in the hybrid system.

- Primary load of the library is considered varying between $0.25 \mathrm{kWh} / \mathrm{d}$ and $1.0 \mathrm{kWh} / \mathrm{d}$ in order to observe and determine the effects of growing primary load values on the economical parameters.

After the simulation of the hybrid system described in the previous sections, the following figure including parameters wind speed, primary, COE and optimal system type is obtained.

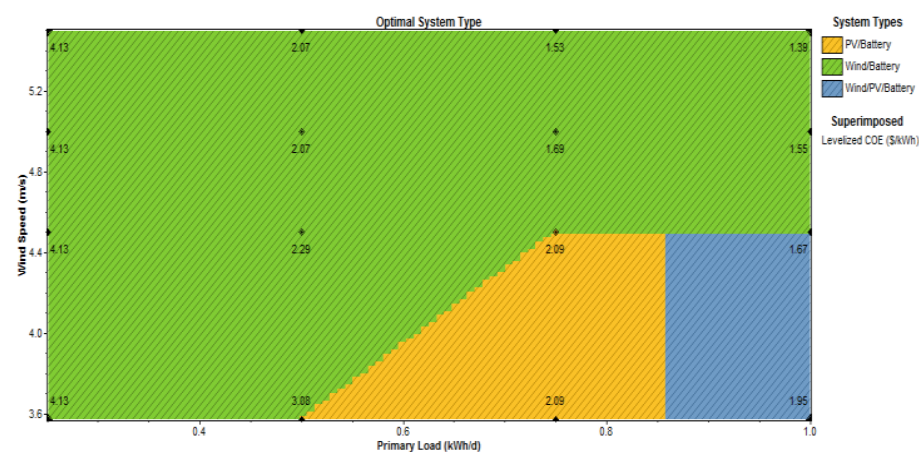

Fig. 9. Optimal System Type in Kırklareli Public Library

It is possible to get some important points from Figure 9. These are:

- There are three alternative hybrid systems which could be applied to meet the electricity demand of Kirklareli public library: Wind/Battery hybrid system, PV/Battery hybrid system and Wind/PV/Battery hybrid system.

- It is understood from Figure that Wind/Battery hybrid system can be commonly used, and it appears to be more preferable than the other hybrid systems.

- According to the figure 9, the COE for any hybrid systems is getting lower while the wind speed value increases.

- No matter what the wind speed is, for all the primary load values which are less than or equal to $0.6 \mathrm{kWh} / \mathrm{d}$, it is easily understood that use of Wind/Battery hybrid system in the public library seems reasonable and that no other alternative hybrid systems could be applied here.

- For the primary load values in the range of 0.5-0.75 $\mathrm{kWh} / \mathrm{d}$, there are two alternative hybrid systems, PV/Battery and Wind/Battery hybrid system, which can be applied to provide the electricity demand of the library depending on the wind speed value. There is no other alternative hybrid system that can be utilized here.

- For the primary load with more than $0.86 \mathrm{~kW} / \mathrm{d}$ values, we have two alternative hybrid systems, namely, Wind/PV/Battery and Wind/Battery hybrid system. It is conspicuous from the figure that the use of PV/Battery hybrid system in the public library seems needless.

\section{CONCLUSIONS}

This study researches the hybrid systems which completely support the preservation of the natural environment and endeavors to eliminate pollution. For this end, renewable fraction of the hybrid power system is considered as $100 \%$.
Under the current conditions, according to the simulation results, the optimal configuration with the lowest total net present cost (NPC) contains one wind turbine, two batteries, and the $1 \mathrm{~kW}$ converter for a public library. The total NPC of the optimal configuration described in the part of discussion is estimated to be $\$ 4319$ and its COE is about $4.127 \$ / \mathrm{kWh}$.

On carrying out a sensitivity analysis in terms of some primary loads varying between $0.25 \mathrm{kWh} / \mathrm{d}$ and $1.0 \mathrm{kWh} / \mathrm{d}$ and wind speed values varying between $3.5 \mathrm{~m} / \mathrm{s}$ and $5.5 \mathrm{~m} / \mathrm{s}$, it can be found out that Wind/Battery hybrid system has more reasons to be preferred than the other hybrid systems.

\section{REFERENCES}

[1] W. Zhou, C. Lou, Z. Li, L. Lin, H. Yang, "Current status of research on optimum sizing of stand-alone hybrid solar-wind power generation systems Applied Energy, Vol.87, 2010, pp. 380-389.

[2] R.M. Moharil, P.S. Kulkarni, "A case study of solar photovoltaic power system at Sagardeep Island, India", Renewable and Sustainable Energy Reviews, Vol.13, 2009, pp. 673-68.

[3] M.A. Elhadidy, "Performance Evaluation of Hybrid (Wind/Solar/Diesel) Power Systems", Renewable Energy, Vol.26, 2002, pp. 401-413.

[4] S. Taskin, B.Dursun and B. Alboyaci, "Performance Assessment Of A Combined Solar And Wind System", The Arabian Journal for Science and Engineering, Vol. 34, No:1B, 2007, pp.217-227.

[5] Report on Public Libraries, Available from http://www.pulmanweb.org/countries/Turkey.htm

[6] B. Yılmaz, "Public Libraries In Turkey", Bibliothek Forschung und Praxis. Vol.32, No:2, pp. 214-217.

[7] B. Dursun "Determination of the optimum hybrid renewable power generating systems for Kavakli campus of Kirklareli University Turkey", Renewable and Sustainable Energy Reviews, Vol.16, No:8, 2012, pp. 6183-6190.

[8] C. Gokcol, B. Dursun, "Determination Of The Optimum Renewable Power Generating Systems For An Educational Campus In Kirklareli University” Electronic Journal of Vocational Colleges, Vol.1,No:1, 2011 pp. $8-17$

[9] TSMS, Turkish State Meteorological Service, 2013, Ankara, Turkey Available from http://www.mgm.gov.tr/en-US/forecast-5days.aspx

[10] HOMER, Software Version 2.67,National Renewable Energy Laboratory (NREL), USA (2011) http://www.nrel.gov/Homer.

[11] T. Lambert, P. Gilman, P. Lilienthal, "Micropower system modeling with HOMER" F.A. Farret, M.G. Simoes (Eds.), Integration of Alternative Sources of Energy, John Wiley \& Sons Inc., USA (2006), pp. 379-418

[12] CPVM, (2011). 100W Solar Panel -100W 12V Crystalline PV Module Available from http://www.cdtsolar.com/100 watt

[13] SW AIR X, 2013, Southwest Windpower, Available from http://www.windenergy.com/products/air/air40.html

[14] DCSS, Deep Cycle-Solar Series 5000, (2011). 6 Cs25ps Battery Available from http://www.dcbattery.com/rollssurrette_6cs25ps.pdf.

\section{BIOGRAPHY}

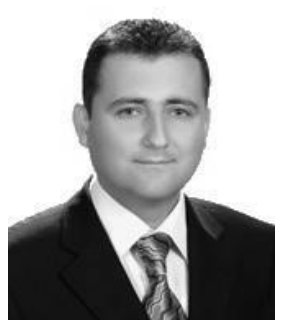

BAHTIYAR DURSUN was born in Istanbul in Turkey. He received the B.Sc. and M.Sc. degrees from Marmara University, Turkey. He obtained the $\mathrm{Ph} . \mathrm{D}$. degree in 2010 from Kocaeli University. From 2004 to 2008, he worked at Gebze Institute of Technology as a Research Assistant. Since 2008, he has been with the Energy Systems Engineering Department of Kurklareli University, Turkey as an Associate Professor. 